\title{
Realities in scholarly publication trends: A case study of a social science university in Taiwan
}

\author{
Wen, Tzi Sin \\ National Open University, Taiwan, ROC (kksunnccu@gmail.com)
}

Ching, Gregory S.

Lunghwa University of Science and Technology, Taiwan, ROC (gregory_ching@yahoo.com)

Tang, Jia Wei

Education Bureau, New Taipei City, Taiwan, ROC (95152508@nccu.edu.tw)

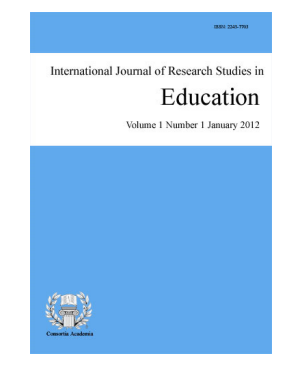

ISSN: 2243-7703 Online ISSN: 2243-7711

OPEN ACCESS

\section{Abstract}

For the past decade, the increasingly globalizing phenomenon of the academe have cause dynamic changes in the character and functions of education in most countries. Similarly, in East Asia, the island state of Taiwan has been undergoing remarkable changes in its higher education. Policy with strong emphasis on the quest for world-class universities was adopted, giving rise to the use of quantifiable variables to measure the quality in research. Knowledge production has been characterized by internationalization and competition, which is governed to an increasing degree through practices based on market-like operations. This case study takes this phenomenon as an indicator of the challenges facing the different level of Taiwan's higher education academe. A comprehensive social science public university in Taiwan, was selected as the venue of this interpretive evaluative case study. Interviews were conducted on participants selected using the maximum variation sampling method. Findings confirmed that knowledge production is governed to a rising scale through practices based on market-like operations. Contrasting views was seen in the social sciences and natural sciences publication practices. In addition, the quality of research is increasingly being connected with the journals indexed in the Thomson Reuters Institute of Scientific Information's (ISI) databases, which is mostly dominated by the Anglo-American journals.

Keywords: publication; citation index; ISI; bibliometric database; case study 


\section{Realities in scholarly publication trends: A case study of a social science university in Taiwan}

\section{Introduction}

The advent of globalization has caused a number of modern states to rethink their educational governance strategies, in order to cope with the rapid social and economic changes (Mok, 2006). Similarly, the processes of globalization have prompted individual states to change their roles and reform their academic institutions in order to adapt and accommodate the demands and pressures generated from the external environments (Mok \& Currie, 2002). Altbach (2004) mentioned that higher education institutions have always figured in the global environment and thus been affected by circumstances beyond the campus and across national borders. However, changes in the nation-state's international relations coupled with the information technology advancement, expansion of business and commerce, and the increasing mobility in the workplace, has undoubtedly increasing the demand on higher education (Knight, 2006). Thus, higher education has assumed unprecedented importance, both within countries and internationally, because of its roles in educating people of the new economy and in creating new knowledge (Altbach, 1998).

Taiwan's higher education has also been undergoing remarkable changes in the past few years. Policy with strong emphasis on the quest for world-class universities was adopted, giving rise to the use of quantifiable variables to measure quality in research. Since the 1990s, Taiwan's higher education has been influenced by three major factors globalization, marketization, and standardization (Mok, 2000). These factors gave way to the rise of the global academic capitalism, which eventually dictates the quality of research. Knowledge production has been characterized by internationalization and competition, which is governed to an increasing degree through practices based on market-like operations. The norm quality of research is increasingly being connected with the journals indexed in the Thomson Reuters Institute of Scientific Information's (ISI) databases, which are dominated mostly by the Anglo-American journals. Eventually, these events generated the start of a debate in what have been dubbed as the global academic standards; which is to have publications in journals indexed in the Science Citation Index (SCI) and Social Science Citation Index (SSCI).

This article details an interpretive evaluative case study conducted during the 2008-2009 academic year to examine the challenges facing a national social science university in Taiwan. To begin, the conceptual framework of the study is defined. Next, a description of the research setting is provided which leads into an outline of the methodological framework of the study. This is then followed by the discussion of results, which situates implications within the different levels of academe in the context of Taiwan's higher education. Findings are offered as a point of reference for contemporary visions of the internationalization of higher education in the age of globalization.

\section{Literature review}

\subsection{Globalization and Higher Education}

Recent years, globalization has caused strong impact in the higher education academe, which is largely reflected in developed countries such as the United States, United Kingdom, Australia, New Zealand, and several Asian societies as well (Mok, 2003, 2007; Ntshoe, 2004). Friedman (2005) mentioned that globalization in our age started from the fall of the Berlin wall and the launch of the world wide web in 1989. Many people have talked about the impact of globalization on economic, social, political, and cultural fronts, for over the past decade or so (Giddens, 1990, 1999; Robertson, 1995; Sklair, 1995). According to Currie (1998), even though globalization is termed differently in different contexts (such as McDonaldization, Toyotism, and post-Fordism 
or neo-Fordism) and each takes a slightly different form, they all emphasize economic efficiency, and there is a tendency towards homogenizing practices. More than ever before, the higher education sector is expected to respond to the increasingly globalized knowledge-intensive world of the twenty-first century (CHE Report, 2000).

According to the data released by OECD (2006), the share of total research expenditures held by governments shows that France has the highest percentage, at about $40 \%$ of its expenditures, and an average of $33 \%$ for OECD countries. However, with the increasingly limited number of resource available and knowing the fact that making a world class university is rather quite expensive, governments have to make the very best decision on which are the better researches that are worth investing. Likewise, countries in East Asia driven by the intention of enhancing their global competitiveness have started to take serious steps. Since the 1990s, Hong Kong higher education has gone through several Research Assessment Exercises (RAEs) patterned from the UK approach to monitor research performance (Mok \& Chan, 2001). Universities in Hong Kong have gone through major review exercises, identifying their major strengths and developing their centre of excellence (Deem, Mok, \& Lucas, 2008). With the adaptation of publish or perish context, Hong Kong academe are becoming more instrumental when choosing publication venues (Mok, 2005). Publications in the SSCI and SCI indexed journals are major target of Hong Kong academe, which is of great concern of the university administrators (Chan, 2007).

In mainland China, in order to enhance the international competitiveness of Chinese universities in the globalizing world, the Chinese government has implemented major projects such as the 211 project and the 985 program, in pursuit of becoming world-class universities (Mok \& Chan, 2001). Recognizing the increased global competition among universities and the pressure brought forth by the university rankings, the Chinese government has strategically identified key national bases for humanities and social sciences research, and major national laboratories have been established to promote scientific research (F. T. Huang, 2006).

In Taiwan, the government has realized that globalization has accelerated competition among higher education institutions globally (Deem et al., 2008). A series of large scale projects were launched, in order to catch up with the world in terms of higher education amid the powerful trend of globalization (Song \& Tai, 2007). Two main focused are internationalization, and the quest for world-class universities. These demands have become even more critical, requiring higher education to respond in an intentional and comprehensive way. Liu (2007) noted that the Taiwan's Higher Education Evaluation and Accreditation Council (HEEACT) was created in 2002 with the single purpose of conducting university evaluations. Through administering evaluations, the HEEACT aims to create an impact on Taiwan's universities and their teachings, and continues to raise standards in the entire higher education system (Liu, 2007). The current increased interest in higher education performance assessments goes beyond higher education institutions (HEI), Ministry of Education (MOE), and the nation itself. Similarly, the focus on performance indicators is not only a response to local or particular conditions, but also represents a general issue which spans a diversity of levels and areas.

\subsection{Standardization and Higher Education}

Globalization has meant an increased demand from students, employers, and academics for indicators of the international standing of universities (Williams \& Dyke, 2004). According to the widely cited ranking published by Shanghai Jiao Tong University (SJTU), indicators used for research quality evaluation wherein articles published in Nature and Science and Articles in SCI-expanded, SSCI each has a weight of 20\% (ARWU, 2007). In other words, when it comes to what makes the best research; people tend to relate it with studies indexed on Nature and Science, SCI and SSCI, which are products of Thomson Reuters. Similarly, in the Asia's Best Universities published by Asia Week, one important indicator for research performance is citations in academic journals as tracked by the Journal Citation Index (Asia Week, n. d.). The citation data which come from Thomson Reuter's Essential Science Indicators were also used in the world university ranking system conducted by Times Higher Education Supplement. 
FSU (2007) noted that citation indexes are bibliographic indexes which allows the user to trace research from an article, by searching for subsequent articles that have cited that original article. These database are mostly used in bibliometrics; a type of research method used in library and information science. Researchers mostly use bibliometric methods to evaluate and determine the influence of a single writer, or the relationship between two or more writers from works within a given field or body of literature. The SCI, the SSCI, and the Arts and Humanities Citation Index (A\&HCI) are some of the most commonly used bibliometric tools for researchers (Palmquist, 2001). While most authors and researchers think that citation indexes are mere tools as means of recovering information, in fact there are actually numerous important, productive and unique uses of such indexes (Garfield, 1994a). Besides that SSCI does produce valid estimates of research quality (Keen, Horan, Hanish, Copperstone, \& Tribbensee, 1998), such indexes can also be used to rank and evaluate journals (Garfield, 1972).

Another important purpose of such indexes is the revelation of connections between ideas or concepts (Garfield, 1994b, 2006). At the same time, mapping researchers and studies with respect to time and field could also be done (Garfield, 1993). Other functions include discovering who is citing your research and the impact your work is having on the global research community. Determine if a theory has been confirmed, changed or improved and find information on how a basic concept is being applied. Track a topic through years of research literature and verify the accuracy of references, could be done by using these indexes (Thomson, 2008).

In addition, there is also an increased tendency of using the frequency of the citation indexes, in work appointment, tenure and/or promotion (Kokko \& Sutherland, 1999), or even funding decisions (Bauer \& Bakkalbasi, 2005). Still, there exists much criticism in the use of these tools in evaluating research performance (Ackermann, 2001). However, Garfield (2005) mentioned that a better evaluation system would involve actually reading each article for quality but then the problem of reconciling peer review judgments would take shape. Evidence do shows the validity of citation criteria as a measure for assessing the impact of scientific scholarship (Lawani \& Bayer, 1983). However, still some claims that ISI citation indexes are far from objective, that the impact that its journals have is a bit illusory, and that the word global stretches the truth about the master journal list (Cruz, 2007). Using the English language as the medium on academic writing also brought forth much problems to those non-English first language countries (Cruz, 2007; Paasi, 2005), which also present in the fields of social science and humanities (Archambault, Vignola-Gagné, Côté, Larivire, \& Gingrasb, 2006).

Bauer \& Bakkalbasi (2005), mentioned that the ISI citation indexes do indeed offers the most comprehensive coverage back in time, but for some subject areas specialized database may offer the best citation coverage, and for yet other areas Google Scholar may be an indispensable tool. However with the continued changes brought forth by advancement of information technology, in addition with the corresponding proliferation of resources that offers both citation indexing and tracking researchers; authors would indeed have more and more tools to aid their academic endeavors.

\subsection{Scholarly Publication in Taiwan}

According to the operations book of MOE (2007b), the numbers of publication in the SCI, SSCI, and AHCI are the data that the HEEACT request for during evaluation. Universities tend to provide these publication numbers in order to convince evaluation commissioners on their achievements in research. In addition, the HEEACT also published the publication numbers of each university in their website. This tends to establish a certain kind of benchmark regarding to the institution's performance. Similarly, parents and students also tend to utilize this information in making their school choice. However, there is no clear regulation (policy) stating the use of such publication numbers of SCI, SSCI, and AHCI in higher education evaluation (MOE, 2007a).

Lai (2004) noted that the information regarding the SCI, SSCI, and A\&HCI publication numbers have caused two negative effects. First, colleges and universities compete in recruiting scholars who has a large amount of publications, thereby creating a false appearance of high academic achievement. Second, universities 
create policies to encourage colleagues to contribute to English journals, hence, professors who publish in Chinese seems to become second-tier scholars. While Huang's (2004) noted that the creation of the Taiwan SSCI is a good way to solve the problem, which SSCI has brought about in the social science arena. Furthermore, publication numbers should not be the only standard of higher education evaluation. In addition, Ye (2004) also noted that the social sciences is mostly concern about the local or national issues. These are historical-based and cultural-based research fields', which works are difficult to translate into English. Even if we translate these works into English; due to its contextual content it is still rather difficult for foreign researchers to fully grasp the issues being discussed.

Chen and Qian (2004) noted that the use of such publication numbers as a kind of global academic standards have cause some unintended consequence in Taiwan, namely: publications in the English language have become more important than the local Chinese language; mainstream international issues have become the center stage in research, rather than the local regional contextual issues; and publications in a foreign English journal have become a more prestigious accomplishment as in publishing in a local regional journal, which suggests that the language being used (English) has become more important than the quality of the paper. These reservations have cause serious debate in the academe, upon the validity of such global academic standards. Opinions and views of supporters and non-supporters alike are both deranged and biased. In light of these issues, this study intends to gain further insight and clear up some issues behind these debates.

\section{Modes of Inquiry}

This case study is focus on a national university in Taipei, Taiwan. The university is a comprehensive public university founded in 1927, ranking the first in the field of Social Sciences, Business Administration, and Communication in Taiwan. Currently, the university has 9 colleges, 33 departments, 56 research centers, and 49 graduate institutes that offer master and doctoral programs. This university was selected as the subject of the case study, because during the process of the literature review, most of the debate on global academic excellence and standards was geared on the field of social sciences. Hence, the current case being the top institution of social sciences in Taiwan, at the same time having a strong science department, constitute a perfect exemplar to understand globalization as a process mediated though education.

The research followed the format of an interpretive evaluative case study. Yin (1989) defines a case study as an empirical inquiry that investigates a current occurrence within its real life context, when the boundaries between the phenomenon and situation are not clearly apparent and in which multiple sources of evidence are used. This single phenomenon is of a bounded system, as in a student, a class, a school, a community. It provides a unique example of real people in real situations, enabling readers to understand ideas more clearly than simply by presenting them with abstract theories or principle (Nisbet \& Watt, 1984). This study uses the standardized open-ended form of interview to gather the different perspectives of the participants. Patton (1980) mentioned that in a standardized open-ended interviews, the exact wording and sequence of questions are determine in advance. All interviewees are asked the same basic questions in the same order. Participants answer the same questions, thus increasing comparability of responses; data are complete for each person on the topics addressed in the interview.

The maximum variation sampling method was also adapted in choosing the participants. This type of strategy involves a deliberate hunt for negative or disconfirming instances or variations of the phenomenon (Miles \& Huberman, 1994). Patton (1990) also added that, findings from even a small sample of great diversity yields important shared patterns that cut across cases and derive their significance from having emerged out of heterogeneity. For data analysis, the constant comparative method was used as the means of developing a grounded theory (Glaser \& Strauss, 1967). A grounded theory consists of categories, properties, and hypotheses that are the conceptual links between and among the categories and properties.

Participants of the case study where two college deans: Dean A; from the field of social sciences and Dean 
B; from the field of Science. Selection of the interviewees was pre-determined to accommodate the views and opinions coming from the fields of social science and science. The goal of the present study was to gain further insight and clear up some issues behind these debates.

\section{Results and Discussions}

After the data were analyzed some themes which are both contradicting and similar in essence emerged. Discussions regarding the influence of the used of global academic standards in Taiwan is done in the different levels of the academe, namely: individuals, fields, and institutions. Both deans mentioned that contrary to the case of Taiwan, in the United States SCI and SSCI are not regarded as important criteria in academic evaluation. Dean A mentioned that "...actually, SCI/SSCI is only a US academic database...", "...however, recently it has been used for academic evaluation and ranking..." Dean B added that "...SCI/SSCI has great implications on the pursuit of Taiwan's universities to become internationalize...” Since 2005, SCI and SSCI have been included as one of the criteria in HEEACT. These in turn caused different implications and impacts to the various levels of the academe.

\subsection{Influence on individuals}

Dean B mentioned that since SCI/SSCI is included as one of the criteria in academic evaluation, individuals would prefer to publish in SCI/SSCI journals. However, in the interviewed with Dean A, he mentioned that the reactions of individuals to $\mathrm{SCI} / \mathrm{SSCI}$ could be grouped into 3 categories:

Dxtreme antagonist - these individuals tend to strongly criticize the adaptation of SCI/SSCI;

> Mainstream followers - most individuals tend to feel uncomfortable regarding this norm, but they would accept it without much reflection. They follow the administrative policy, just for the sake of getting reward or promotion;

$>$ Supporters - those individuals who are good in using English as the medium of writing papers or those individuals who comes from specific fields.

\subsection{Influence on fields}

From the perspective of an individual, SCI/SSCI has more or less influence their behavior in academic publications. However, if individuals are grouped into two fields' namely social science and science, the influence of SCI/SSCI would have obvious disparity. As in the field of science, Dean B said “....it doesn't matter whether MOE's use SCI/SSCI as evaluation criteria or not, because publication in SCI journals is already their norm, and for example like myself, there is only one Taiwan journal in the field of computer science..."

On the other hand, Dean A said "...SCI/SSCI is an important criterion for the field of science but not for the case of social science, because in the field of social science research it's quite hard to strike a balance between localization and globalization...", "...if most social science research are based on SCI/SSCI journals, this would cause negative influence in the local arena..." Dean B has some similar views he said that "...the laboratory rats used in laboratory experiment in the US and Taiwan are not that different...", "...therefore, the research findings could be easily adopted and applied locally..."

\subsection{Influence on institutions}

Besides the influence on individual and field, SCI/SSCI influence on institution is even greater than the later two. Dean A said “....the institution's stress is far greater than of the individual professors, because institutions should maintain their image and competiveness...", "...the standard of these competition does not reflect the ideal value of social science, and however, institutions have no choice but to employ these policy to encourage SCI/SSCI publications...” 
On the other hand, Dean B mentioned that "...the core value of modern university is knowledge innovation...", “...international competitiveness lies on one country's research productivity in which NCCU lacks..." He also stressed "...that SCI/SSCI might be flawed, but at least it could serve as a clear and concrete standard for researches...", "...in addition SCI/SSCI has been widely used as a criterion in world higher education/university rankings, therefore it is quite normal to use SCI/SSCI as a criterion for academic evaluation..."

\subsection{Implications}

Recognizing that research and development (R\&D) is important for economic growth, and global competitiveness, the government around the world increased its role in funding $\mathrm{R} \& \mathrm{D}$ activities. International surveys of universities, such as the recent Times Higher World University Rankings 2006, have taken ISI data as crucial determinants of the quality of faculty and research. In order to be ranked internationally and thus to attract both students and funding, universities urge their researchers to publish in ISI journals and to have their works cited by scholars writing in ISI journals. Intellectually and financially, therefore, ISI wields tremendous power over faculty, administrators, publishers, and funding agencies.

To both deans, the final judgment of the research quality lies in experts' opinion. However, they consider that the adoption of the academic standards such as SCI and SSCI are more political in nature than being considered as an expert opinion. In October 2003, the Ministry of Education published the league table of the research assessment of all universities in 2002 based on the total accumulation of papers published in journals listed in SCI and SSCI. Although the government claimed that it will not be the tool for university ranking and evaluation, it has created a tension for scholars in humanity studies as their research and publication are more limited by languages and the context (I. R. Chen, 2006).

After negotiation with experts from all academic filed, the criteria used in 2005 university evaluation, however, still included the papers published in journals listed in SCI and SSCI as important indicator in research quality evaluation. Later on, the MOE launched the Aiming for the Top University and Elite Research Center Development Plan (MEE ATU plan); a competitive funding plan amounting to fifty billion NT\$ is to be distributed over a five-year period. The Vice-Minister of Education Lu, Mu-lin (2003) made the following announcement:

"The Ministry would like at least one of its universities to be ranked among the top 100 leading international institutions of higher education, within the next ten years and to have at least one university ranked as number one, within Asia by the next five years."

To compete for the big amount of money, universities in Taiwan make their best to fit in the image of the so called leading international institutions and world-class universities. Take NCCU for example, departments compete to recruit scholars in the SCI/SSCI publication because the more SCI/SSCI, the higher the prestige. According to Dean B, "if we publish one paper in SCI/SSCI journal, we'll gain 20 thousand NT\$ as reward from NCCU... ", "...if your English is not good enough, it's all right, since you could apply for translation assistance..." hinting the extent of institution's policy in encouraging professors to take part in English academic writing.

Academics all over the world find it prestigious to have their articles published in the journals included in the Master Journal List of Thomson Reuter's ISI. Publishers of non-ISI journals often make it their objective to have their journals listed in ISI, not only because of the prestige, but because librarians usually make decisions on subscriptions based on Thomson Reuter's ISI. Scholars in countries like the Netherlands improved their quality of research by encouraging them to have ISI publications (Nederhof, 2008). Still, numerous institutions in various fields has adopted these bibliometric tools are a form of criterion in evaluating an individuals' productivity (Davis, 1998). 
Thomson Reuter's journal list is not all inclusive; not all journals are included (Cruz, 2007), sometimes even the most well known journal in fields are not included (Eaton, 2007). The fact that almost more than $90 \%$ of these journals are of Anglo-American origin with English language as the main medium of writing (Paasi, 2005; Zitt, Perrot, \& Barre, 1998). Using of these bibliometrics as macro indicator of studies and at the same analyzed a country's publication output per institutional sector would be helpful (Moed, Bruin, \& Van Leeuwen, 1995), but some findings shows that due to rankings and evaluations publications tend to shift from quality to quantity (Moed, 2008).

It is really still a question of the feasibility of using Thomson Reuter's ISI as the facto global academic standards, but due to the increased in commodification of knowledge (Lincoln, 1998), even though that these indexes are strongly biased against culture and language with Anglo-American countries in some fields (Decker, Beutel, \& Brähler, 2004). This transnational corporation is here to stay and its influence on academia would be greater than ever.

\section{Conclusion}

Higher education institutions amidst the changes brought forth by globalization has caused uneven impacts, even through similar business-like processes have been adopted to cope with competition in the global marketplace. The pressure for restructuring and reforming in education is mainly derived from the growing expectations and demands of the different stakeholders in society. Recognizing that research and development is important for economic growth and global competitiveness, consequently governments around the world started to increased its role in funding such activities.

The increased popularity and importance of information technology has unquestionably changed the nature of knowledge and its currently restructuring higher education, research, and learning. Recently, the use computerized databases in the form of bibliographic indexes have become a necessity in higher education research. The transnational journal and book publishing houses are getting larger and more powerful, enhanced by a series of takeovers and mergers, in addition with the advancement of technology (James \& McQueen-Thomson, 2002). Commodification of knowledge (Lincoln, 1998); by having libraries purchase their products in order to keep up with the swift demand for information, which in turn has changed the way academics undergo research. Thus, equating the quality of research in publications in the journals indexed in the ISI databases, which are dominated mostly by the Anglo-American journals.

The impact of global academic standards is clearly present in all levels, but varies in terms of intensity. Higher education institution amidst the problems brought forth by funding allocation, academic evaluation, and internationalization has caused various issues and problems. The National higher education evaluation dimensions would tend to affect institutions' policies. However, due to the contrasting views on global academic standards, Taiwan's higher education evaluation policies have begun to undergo changes. Individuals from social sciences and natural sciences have very contrasting views on the impact of such global academic standards. The factors of their attitude diversity come from their research field, English ability, personal experience and personal value.

The negative influence of global academic standards to social science research field is mentioned by both of the deans. The dean who comes from social science research field strongly questions the appropriateness of SCI/SSCI system as the main standard to evaluate the value of localized and local-based researches. On the other hand, both of the deans agree that SCI system brings fewer problems to science. The key-factor which brings this kind of variation is the field's context; social sciences are different from the sciences. Social sciences should serve the needs of the local society, and should therefore make efforts to rid itself from its dependency on affirmation from the West, which has undoubtedly changed its publication landscape. Publication numbers are not equal to the total academic achievement of a university, a department or a scholar. Statistics of the publications is just one of the tools to evaluate a university's performance. It is not the only tool, and more 
Realities in scholarly publication trends: A case study of a social science university in Taiwan

importantly, it is not the aim of higher education. Both universities and scholars should understand the true meanings and duties of education and academic evaluation.

\section{References:}

Ackermann, E. G. (2001). Developing comparative bibliometric indicators for evaluating the research performance of four academic nutrition departments, 1992-1996: An exploratory study. University of Tennessee, Knoxville.

Altbach, P. G. (1998). Comparative higher education: Knowledge, the university, and development. Greenwich, CT: Ablex.

Altbach, P. G. (2004). Globalisation and the university: Myths and realities in an unequal world. Tertiary Education and Management, 10, 3-25. <http://dx.doi.org/10.1080/13583883.2004.9967114>

Archambault, É., Vignola-Gagné, É., Côté, G., Larivire, V., \& Gingrasb, Y. (2006). Benchmarking scientific output in the social sciences and humanities: The limits of existing databases. Scientometrics, 68(3), 329-342. <http://dx.doi.org/10.1007/s11192-006-0115-z>

ARWU. (2007). Academic ranking of world universities. Retrieved November 8, 2007, from http://www.arwu.org/rank/2007/ARWU2007_Top100.htm

Asia Week. (n. d.). Asia's best universities 2000. Retrieved January 5, 2006, from http://www.asiaweek.com/asiaweek/features/universities2000/schools/multi.overall.html

Bauer, K., \& Bakkalbasi, N. (2005, September). An examination of citation counts in a new scholarly communication environment. D-Lib Magazine, 11 .

Chan, D. (2007). Global agenda, local responses: Changing education governance in Hong Kong. Globalisation, Societies \& Education, 5(1), 109-124. <http://dx.doi.org/10.1080/14767720601133504>

CHE Report. (2000). Towards a new higher education landscape: Meeting the equality, quality and social development imperatives of South Africa in the 21st century (pp. 5). Pretoria.

Chen, I. R. (2006). Pursuing excellence: Quality assurance in Taiwanese higher education, GDPism and riskChallenges for social development and governance in East Asia. Paper presented at the Third Asian Social Policy Research Network International Conference.

Chen, K. S., \& Qian, Y. X. (2004). Academic production under the Neo-liberalism globalization [In Chinese]. Paper presented at the Reflecting on Taiwan's Higher Education Academic Evaluation Conference.

Cruz, I. (2007). Challenging ISI Thomson Scientifics' journal citation reports: Deconstructing "Objective", "Impact", and "Global". Retrieved January 4, 2008, from http://scholarlypublishing.blogspot.com/2007/07/challenging-isi-thomson-scientifics.html

Currie, J. (1998). Globalization practices and the professoriate in Anglo-Pacific and North American universities. Comparative Education Review, 24(1), 15-29. <http://dx.doi.org/10.1086/447476>

Davis, J. B. (1998). Problems in using the social sciences citation index to rank economics journals. American Economist, 42(2), 59-64.

Decker, O., Beutel, M. E., \& Brähler, E. (2004). Deep impact - Evaluation in the sciences. Social and Preventive Medicine, 49(1), 10-14.

Deem, R., Mok, K. H., \& Lucas, L. (2008). Transforming higher education in whose image? Exploring the concept of the world-class university in Europe and Asia. High Education Policy, 21(1), 83-97. $<$ http://dx.doi.org/10.1057/palgrave.hep.8300179>>

Eaton, J. (2007). Fine tuning English writing workshop - September 14-15, 2007. National Taiwan University of Science and Technology: Taiwan Assessment and Evaluation Association.

Friedman, T. (2005). The world is flat: A brief history of the twenty-first century. New York: Farrar, Straus and Giroux.

FSU. (2007). Library terms. Retrieved January 5, 2008, from http://www.lib.fsu.edu/help/libraryterms

Garfield, E. (1972). Citation analysis as a tool in journal evaluation: Journals can be ranked by frequency and impact of citations for science policy studies. Science, 178(4060), 471-479.

<http://dx.doi.org/10.1126/science.178.4060.471> 
Wen, T. S., Ching, G. S., \& Tang, J. W.

Garfield, E. (1993). What citations tell us about Canadian research. Canadian Journal of Information and Library Science, 18(4), 14.

Garfield, E. (1994a). The concept of citation indexing: A unique and innovative tool for navigating the research literature. Retrieved January 6, 2008, from http://scientific.thomson.com/free/essays/citationindexing/concept/

Garfield, E. (1994b). Linking literatures: An intriguing use of the citation index. Retrieved January 5, 2008, from http://scientific.thomson.com/free/essays/useofcitationdatabases/linking/

Garfield, E. (2005). The agony and the ecstasy - The history and meaning of the journal impact factor. Paper presented at the International Congress on Peer Review And Biomedical Publication.

Garfield, E. (2006). Citation indexes for science. A new dimension in documentation through association of ideas. International Journal of Epidemiology 35(5), 1123-1127.

Giddens, A. (1990). The consequences of modernity. Cambridge: Polity Press.

Giddens, A. (1999). Runaway world. London: Profile Books Limited.

Glaser, B. G., \& Strauss, A. L. (1967). The discovery of grounded theory. Chicago: Aldine.

Huang, F. T. (2006). Difference in the context of internationalization by region: China. In N. Furushiro (Ed.), Final report of developing evaluation criteria to assess the internationalization of universities (pp. 56-70). Kwansei: Osaka University

Huang, H. M. (2004). SSCI, TSSCI and Taiwan social science evaluation system [In Chinese]. Paper presented at the Reflecting on Taiwan's Higher Education Academic Evaluation Conference.

James, P., \& McQueen-Thomson, D. (2002). Abstracting knowledge formation: A report on academia and publishing. In C. S. (Ed.), Scholars and Entrepreneurs (pp. 183-206). Melbourne: Arena.

Keen, B., Horan, J. J., Hanish, C., Copperstone, J., \& Tribbensee, N. (1998). Publication frequency, citation frequency, and quality of counseling psychology research. Paper presented at the Annual meeting of American Psychological Association. Retrieved January 5, 2008, from http://horan.asu.edu/d-bk-apa.htm

Knight, J. (2006). Internationalization: Concepts, complexities and challenges In J. Forest \& P. G. Altbach (Eds.), International handbook of higher education. Netherlands: Springer.

Kokko, H., \& Sutherland, W. J. (1999). What do impact factors tell us? Trends in Ecology \& Evolution 14(10), 382-384. <http://dx.doi.org/10.1016/S0169-5347(99)01711-5>

Lai, D. M. (2004). Quantitative indexes are not the panacea of academic evaluation [In Chinese]. Paper presented at the Reflecting on Taiwan's Higher Education Academic Evaluation Conference.

Lawani, S. M., \& Bayer, A. E. (1983). Validity of citation criteria for assessing the influence of scientific publications: New evidence with peer assessment. Journal of the American Society for Information Science, 34(1), 59. <http://dx.doi.org/10.1002/asi.4630340109>

Lincoln, Y. S. (1998). Commodification and contradiction in academic research. Studies in Cultures, Organizations, and Societies, 4, 263-278. <http://dx.doi.org/10.1080/10245289808523515>

Liu, W. C. (2007). Message from the chairman. Retrieved October 27, 2008, from http://www.heeact.edu.tw/

Lu, M. L. (2003). The making of world class research universities in an age of globalization - Components \& challenges. Retrieved January 5, 2008, from http://www.edu.tw/EDU_WEB/EDU_MGT/BICER/EDUANDY001/english/ebc.pdf

Miles, M. B., \& Huberman, A. M. (1994). Qualitative data analysis (2nd ed.). Thousand Oaks, CA: Sage.

MOE. (2007a). University's research achievement. Retrieved January 8, 2008, from http://rd.shu.edu.tw/a70/delp/\%A4j\%BE\%C7\%AE\%D5\%B0\%C8\%B5\%FB\%C5\%B2\%B3W\%B9\%BA \%BBP\%B9\%EA\%ACI\%ADp\%B5e(\%B1\%D0\%A81\%B3\%A1\%B8\%C9\%A5R\%BB\%A1\%A9\%FA).d $\underline{\mathrm{OC}}$

MOE. (2007b). University evaluation memorandum. Retrieved January 8, 2008, from http://www.edu.tw/EDU_WEB/EDU_MGT/HIGH/EDU5128001/unerversity\%20school\%20evaluation. $\underline{\mathrm{doc}}$

Moed, H. F. (2008). UK Research Assessment Exercises: Informed judgments on research quality or quantity? Scientometrics, 74(1), 153-161. <http://dx.doi.org/10.1007/s11192-008-0108-1> 
Realities in scholarly publication trends: A case study of a social science university in Taiwan

Moed, H. F., Bruin, R. E. D., \& Van Leeuwen, T. N. (1995). New bibliometric tools for the assessment of national research performance: Database description, overview of indicators and first applications Scientometrics, 33(3), 381-422. <http://dx.doi.org/10.1007/BF02017338>

Mok, K. H. (2000). Reflecting globalization effects on local policy: Higher education reform in Taiwan. Journal of Education Policy, 15(6), 637-660. <http://dx.doi.org/10.1080/02680930010000236>

Mok, K. H. (2003). Similar trends, diverse agendas: Higher education reforms in East Asia. Globalisation, Societies and Education, 1(2), 201-221. <http://dx.doi.org/10.1080/14767720303910>

Mok, K. H. (2005). The quest for world class university: Quality assurance and international benchmarking. Quality Assurance in Education, 13(4), 277-304. <http://dx.doi.org/10.1108/09684880510626575>

Mok, K. H. (2006). Education reform and education policy in East Asia. New York, NY: Routledge.

Mok, K. H. (2007). Globalisation, new education governance and state capacity in East Asia. Globalisation, Societies \& Education, 5(1), 1-21. <http://dx.doi.org/10.1080/14767720601133009>

Mok, K. H., \& Chan, D. (2001). Educational reforms and coping strategies under the tidal wave of marketisation: A comparative study of Hong Kong and the mainland [1]. Comparative Education Review, 37(1), 21-41. <http://dx.doi.org/10.1080/03050060020020417>

Mok, K. H., \& Currie, J. (2002). Reflections on the impact of globalization on educational restructuring in Hong Kong. In K. H. Mok \& D. Chan (Eds.), Globalization and education: The quest for quality education in Hong Kong. Hong Kong: Hong Kong University Press.

Nederhof, A. J. (2008). Policy impact of bibliometric rankings of research performance of departments and individuals in economics. Scientometrics, 74(1), 163-174. $<$ http://dx.doi.org/10.1007/s11192-008-0109-0>

Nisbet, J., \& Watt, J. (1984). Case study. In J. Bell, T. Bush, A. Fox, J. Goodey \& S. Goulding (Eds.), Conducting small-scale investigations in educational management (pp. 79-92). London: Harper \& Row.

Ntshoe, I. M. (2004). The politics and economics of post apartheid higher education transformation. Comparative Education Review, 48(2), 202-221. <http://dx.doi.org/10.1086/382623>

OECD. (2006). Education at a glance. Paris: OECD.

Paasi, A. (2005). Globalization, academic capitalism, and the uneven geographies of international journal publishing spaces. Environment and Planning A, 37(5), 769-789. < http://dx.doi.org/10.1068/a3769>

Palmquist, R. A. (2001). Bibliometrics. Retrieved January 5, 2008, from http://www.gslis.utexas.edu/ palmquis/courses/biblio.html\#TOP

Patton, M. Q. (1980). Qualitative evaluation methods. Beverly Hills, CA: Sage.

Patton, M. Q. (1990). Qualitative evaluation methods (2nd ed.). Thousand Oaks, CA: Sage.

Robertson, R. (1995). Globalization: Time-space and homogeneity-heterogeneity. In M. Featherstone, S. Lash \& R. Robertson (Eds.), Global modernities. London: Sage Publications. $<$ http://dx.doi.org/10.4135/9781446250563.n2>

Sklair, L. (1995). Sociology of the global system. Baltimore: John Hopkins University Press.

Song, M.-M., \& Tai, H.-H. (2007). Taiwan's responses to globalisation: Internationalisation and questing for world class. Asia Pacific Journal of Education, 27(3), 323-340. <http://dx.doi.org/10.1080/02188790701594067>

Thomson. (2008). Web of science. Retrieved January 5, 2008, from http://scientific.thomson.com/products/wos/

Williams, R., \& Dyke, N. V. (2004). The international standing of Australian universities. Retrieved January 10 , 2008, from http://www.melbourneinstitute.com/publications/reports/aus_uni/

Ye, Q. Z. (2004). The lack of the sense of social practice: The myth of criterion based evaluation [In Chinese]. Paper presented at the Reflecting on Taiwan's Higher Education Academic Evaluation Conference.

Yin, R. K. (1989). Case study research: Design and methods. Newbury Park, NY: Sage Publications.

Zitt, M., Perrot, F., \& Barre, R. (1998). The transition from "National" to "Transnational" model and related measures to countries performance. Journal of the American Society for Information Science (1986-1998), 49(1), 30-42. 
Wen, T. S., Ching, G. S., \& Tang, J. W. 